\title{
Effects of stress hormones on the production of volatile sulfur compounds by periodontopathogenic bacteria
}

Caroline Morini CALIL(a) Gisele Mattos OLIVEIRA ${ }^{(b)}$ Karina COGO(c)

Antonio Carlos PEREIRA(d) Fernanda Klein MARCONDES(b) Francisco Carlos GROPPO(b)

(a)Halitosis Diagnostic Center - Halicenter, São Paulo, SP, Brazil.

(b)Department of Physiological Sciences, Piracicaba Dental School, University of Campinas - UNICAMP, Piracicaba, SP, Brazil.

(c)Department of Dentistry, Implantology Area, Universidade de Santo Amaro - Unisa, São Paulo, SP, Brazil.

(d) Department of Social and Preventive Dentistry, Piracicaba Dental School, University of Campinas - UNICAMP, Piracicaba, SP, Brazil.

Declaration of Interests: The authors certify that they have no commercial or associative interest that represents a conflict of interest in connection with the manuscript.

Corresponding Author:

Karina Cogo

E-mail: karicogo@hotmail.com

DOI: 10.1590/1807-3107BOR-2014.vol28.0008 Epub Jun 02, 2014

Submitted: Aug 20, 2013

Accepted for publication: Jan 13, 2014

Last revision: Feb 06, 2014

\begin{abstract}
Little is known about the effects of stress hormones on the etiologic agents of halitosis. Thus, the aim of this study was to evaluate in vitro the effects of adrenaline (ADR), noradrenaline (NA) and cortisol (CORT) on bacteria that produce volatile sulfur compounds (VSC), the major gases responsible for bad breath. Cultures of Fusobacterium nucleatum (Fn), Porphyromonas endodontalis (Pe), Prevotella intermedia (Pi) and Porphyromonas gingivalis ( $P g$ ) were exposed to $50 \mu \mathrm{M}$ ADR, NA and CORT or equivalent volumes of sterile water as controls for 12 and 24 $\mathrm{h}$. Growth was evaluated based on absorbance at $660 \mathrm{~nm}$. Portable gas chromatography was used to measure VSC concentrations. KruskalWallis and the Dunn post-hoc test were used to compare the groups. For $F n$, ADR, NA and CORT significantly reduced bacterial growth after $12 \mathrm{~h}$ and $24 \mathrm{~h}(p<0.05)$. All the substances tested increased hydrogen sulfide $\left(\mathrm{H}_{2} \mathrm{~S}\right)$ production $(p<0.05)$. For $P e$, all the substances tested reduced bacterial development after $24 \mathrm{~h}(p<0.05)$, and NA significantly increased the $\mathrm{H}_{2} \mathrm{~S}$ concentration after $12 \mathrm{~h}(p<0.05)$. In the $\mathrm{Pg}$ and $P i$ cultures, no effects on bacterial growth were observed $(p>0.05)$. In the $P i$ cultures, ADR, NA and CORT increased $\mathrm{H}_{2} \mathrm{~S}(p<0.05)$. Catecholamines and cortisol can interfere with growth and $\mathrm{H}_{2} \mathrm{~S}$ production of sub-gingival species in vitro. This process appears to be complex and supports the association between stress and the production of VSC.
\end{abstract}

Keywords: Halitosis; Catecholamines; Hydrocortisone; Gram-Negative Anaerobic Bacteria.

\section{Introduction}

Halitosis, also known as bad breath or malodor, is a term used to describe unpleasant, fetid odors present in air exhaled from the mouth. ${ }^{1}$ Being unpleasant, bad breath is a problem that affects both the patient and the family. ${ }^{1}$

Studies have indicated that in the majority of cases, malodor is associated with the degradation of sulfur-containing amino acids (methionine, cysteine and cystine) by anaerobic gram-negative bacteria present in the oral cavity, including Porphyromonas gingivalis, Fusobacterium nucleatum, Prevotella intermedia, Tannerella forsythia and Porphyromonas endodontalis. ${ }^{2,3}$ Volatile sulfur compounds (VSC), such as hydrogen sulfide $\left(\mathrm{H}_{2} \mathrm{~S}\right)$, methyl mercaptan $\left(\mathrm{CH}_{3} \mathrm{SH}\right)$ and dimethyl sulfide $\left[\left(\mathrm{CH}_{3}\right)_{2} \mathrm{~S}\right]$, are generated as a product of this metabolism. ${ }^{3}$ 
Some patients with halitosis do not present clinical evidence of oral pathologies or systemic disorders. Stress, depression and anxiety have been identified as risk factors for a shift in oral homeostasis. ${ }^{4,5}$ It has been proposed that emotional alterations may be a co-factor in halitosis development. Calil and Marcondes ${ }^{6}$ reported increased VSC concentrations in healthy men faced with an anxiety-evoking situation compared with the basal situation, independent of salivary flow.

The relationship between stress and the progression of infectious diseases, including periodontitis, has been the focus of some studies over the last few decades. ${ }^{4,8,9,9,10}$ However, the mechanisms involved in this process are still not clear. Potentially pathogenic microorganisms can recognize stress hormones, a fact that has led to the development of the concept of "microbial endocrinology."11 These microorganisms could use the hormones produced by the host as 'environmental trails' to initiate their growth and pathogenic processes. ${ }^{12,13,14,15,16,17}$ In one study, the growth rate of bacteria commonly found in the oral cavity, such as Actinomyces naeslundii, Eikenella corrodens, and Campylobacter gracilis, was stimulated by exposure to noradrenaline. ${ }^{13}$ In addition, recent studies show conflicting results of noradrenaline and adrenaline on the growth of $P$. gingivalis, with studies showing either no effects of these hormones on growth ${ }^{12,17}$ or demonstrating a reduction in viability. ${ }^{13,15}$ Recently, it was demonstrated that noradrenaline can stimulate the production and activity of arg-gingipain $B$, an important protease of $P$. gingivalis. ${ }^{15}$ Thus, the effects of stress could be mediated by two potentially synergistic pathways involving the downregulation of the host's defenses and the up-regulation of bacterial pathogenicity.

Because there is clinical evidence that stress is related to halitosis, ${ }^{6}$ we hypothesized that periodontal bacteria would respond to stress substances by stimulating their growth and their production of VSC. Because there have been no studies on the effects of stress hormones on VSC production, the aim of the present study was to investigate the effects of catecholamines and cortisol on the growth and VSC production of periodontopathogens.

\section{Methodology \\ Substances Used}

The following substances were tested: adrenaline - ADR (epinephrine bitartrate, Sigma Chemical Co. ${ }^{\circledR}$, St Louis, USA), noradrenaline - NA (arterenol, Sigma ${ }^{\circledR}$ ) and cortisol - CORT (hydrocortisone, Sigma ${ }^{\circledR}$ ). The $50 \mu \mathrm{m}$ concentration of ADR, NA ${ }^{13,18}$ and CORT ${ }^{19}$ was chosen based on previous studies.The solutions were prepared using distilled water as the solvent and were sterilized using Millex ${ }^{\circledR}\left(\right.$ Millipore $^{\circledR}$, Billerica, USA) sterile filters with a pore size of $0.22 \mu \mathrm{m}$.

\section{Bacterial Samples and Culture Conditions}

The growth patterns and VSC production of four bacterial species (Porphyromonas endodontalis from clinical specimens - Pe, Porphyromonas gingivalis W83 - Pg, Fusobacterium nucleatum nucleatum ATCC 25586 - Fn and Prevotella intermedia ATCC 25611 $\mathrm{Pi}$ ) were examined. These species were selected based on their ability to produce VSC constitutively. The bacteria were grown statically in brain heart infusion broth (BHI; Difco Co., Detroit, USA). To cultivate $P g$ and $P e, 5 \mu \mathrm{g} / \mathrm{mL}$ hemin (Sigma ${ }^{\circledR}$ ) and $1 \mu \mathrm{g} / \mathrm{mL}$ menadione $\left(\operatorname{Sigma}^{\circledR}\right)$ were added to the BHI. Bacterial cultures were grown at $37^{\circ} \mathrm{C}$ under anaerobic conditions $\left(10 \% \mathrm{CO}_{2}, 10 \% \mathrm{H}_{2}\right.$ and $80 \% \mathrm{~N}_{2}$; MiniMacs Anaerobic Workstation, Don Whitley Scientific ${ }^{\circledR}$, Shipley, UK).

\section{Study design and Experimental Groups}

Cultures of $\mathrm{Pg}, \mathrm{Pe}, \mathrm{Pi}$ and $\mathrm{Fn}$ were exposed to 50 $\mu \mathrm{M}$ ADR, NOR and CORT for 12 and $24 \mathrm{~h}$ (early and mid-logarithmic growth phases). Tubes containing bacteria without the tested substances but containing equivalent volumes of distilled water (vehicle) were used as positive control for growth. Negative controls contained only the tested substances and the culture medium. After incubation, bacterial growth and VSC production were assessed as follows. At least two separate experiments were performed for each hormone tested. In each experiment, 8 replicates were tested for each group (ADR, NA, CORT and controls). ${ }^{20}$

\section{Susceptibility Tests (Macrodilution Broth Tests)}

Susceptibility was assayed using a macrodilution broth test as previously described. ${ }^{21}$ Tubes containing 
$5 \mathrm{~mL}$ of BHI broth medium (plus $5 \mu \mathrm{g} / \mathrm{mL}$ hemin $\left(\right.$ Sigma $\left.^{\circledR}\right)$ and $1 \mu \mathrm{g} / \mathrm{mL}$ menadione $\left(\right.$ Sigma $\left.^{\circledR}\right)$ for the $P g$ and $P e$ cultures) were prepared for each experimental group. A standardized bacterial suspension was prepared in sterile saline solution $(0.9 \% \mathrm{NaCl})$ and adjusted with a spectrophotometer (Unico 1100 RS;Unico ${ }^{\circledR}$, Dayton, USA) to an optical density of 0.5 $\left(8 \times 10^{6} \mathrm{CFU} / \mathrm{mL}\right)$. An inoculum of $500 \mu \mathrm{L}$ was added to each tube to give a final concentration of $4 \times 10^{6}$ $\mathrm{CFU} / \mathrm{mL}$. The tubes were then incubated at $37^{\circ} \mathrm{C}$ in anaerobic conditions for 12 or $24 \mathrm{~h}$. After these periods, bacterial growth was assessed spectrophotometrically at a wavelength of $660 \mathrm{~nm}$.

\section{Bacterial VSC Production Tests}

This experiment was conducted as previously described, with some modifications. ${ }^{20}$ For bacterial VSC production analyses, the experimental groups and inocula were prepared as described above. After incubation at $37^{\circ} \mathrm{C}$ in anaerobic conditions, $0.1 \mathrm{~mL}$ of air from the tubes was aspirated using a $1 \mathrm{~mL}$ syringe $\left(\mathrm{BD}^{\circledR}\right.$, Franklin Lakes, USA) coupled to a needle $\left(\mathrm{BD}^{\circledR}\right)$ (Figure 1) and injected into Oral Chroma $^{\circledR}$ (Abimedical, Osaka, Japan). For a period of 8 minutes, the apparatus performed molecule counts in parts per billion ( $\mathrm{ppb}$ ) of hydrogen sulfite $\left(\mathrm{H}_{2} \mathrm{~S}\right)$ and methylmercaptan $\left(\mathrm{CH}_{3} \mathrm{SH}\right)$. VSC analyses were performed at two different time intervals (12 and 24 h). These incubation lengths were chosen because at these periods, the bacteria are growing exponentially, and there are more viable cells than dead cells.

Gaseous standards of the VSC $\left(\mathrm{H}_{2} \mathrm{~S}\right.$ and $\left.\mathrm{CH}_{3} \mathrm{SH}\right)$ were prepared as described previously ${ }^{22}$ by White Martins (Campinas, Brazil) (RBC-INMETRO n M-32433/10), and the device was calibrated every three months according to Tangerman and Winkel. ${ }^{23}$

\section{Statistical Analysis}

Levene's test was used to test the homogeneity of variance, and the normality of distribution was tested by the Shapiro-Wilk's test. Kruskal-Wallis and the Dunn post-hoc test were used to compare the groups (ADR, NA and CORT compared to control for each bacteria and each time interval separately). Statistical analysis was performed using BioEstat 5.0 (Fundação Mamirauá, Belém, Brazil) at a significance level of $5 \%$.

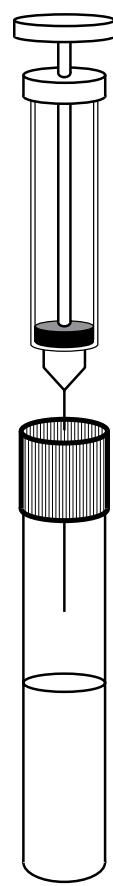

Figure 1. Disposition of the tube, syringe and needle used in the Bacterial VSC Production Tests.

\section{Results Effects of Adrenaline, Noradrenaline and Cortisol on Bacterial Growth}

Figure 2 summarizes the effects of these substances on bacterial growth (optical density, $660 \mathrm{~nm}$ ). For the Fn cultures, ADR, NA and CORT significantly reduced bacterial growth after 12 and $24 \mathrm{~h}$ ( $p<0.05$, Kruskal Wallis test). For Pe, the tested substances reduced bacterial growth, but only after $24 \mathrm{~h}$ of exposure $(p<0.05)$. No statistically significant differences in optical density $(p>0.05)$ were observed for the $P g$ and $P i$ cultures in any of the time periods evaluated.

\section{Effects of Noradrenaline, Adrenaline and Cortisol on Bacterial VSC Production}

The median values and interquartile deviations of $\mathrm{H}_{2} \mathrm{~S}$ and $\mathrm{CH}_{3} \mathrm{SH}$ concentrations (in ppb) for $\mathrm{Fn}$, $\mathrm{Pe}, \mathrm{Pg}$ and $\mathrm{Pi}$ cultures exposed for 12 and $24 \mathrm{~h}$ to ADR, NA and CORT are presented in Figures 3 and 4 , respectively.

In $F n$, only CORT caused a significant increase in $\mathrm{H}_{2} \mathrm{~S}$ levels at $12 \mathrm{~h}$ (Kruskal-Wallis, $p<0.05$ ), while no changes in $\mathrm{H}_{2} \mathrm{~S}$ concentration were observed at $24 \mathrm{~h}$ 


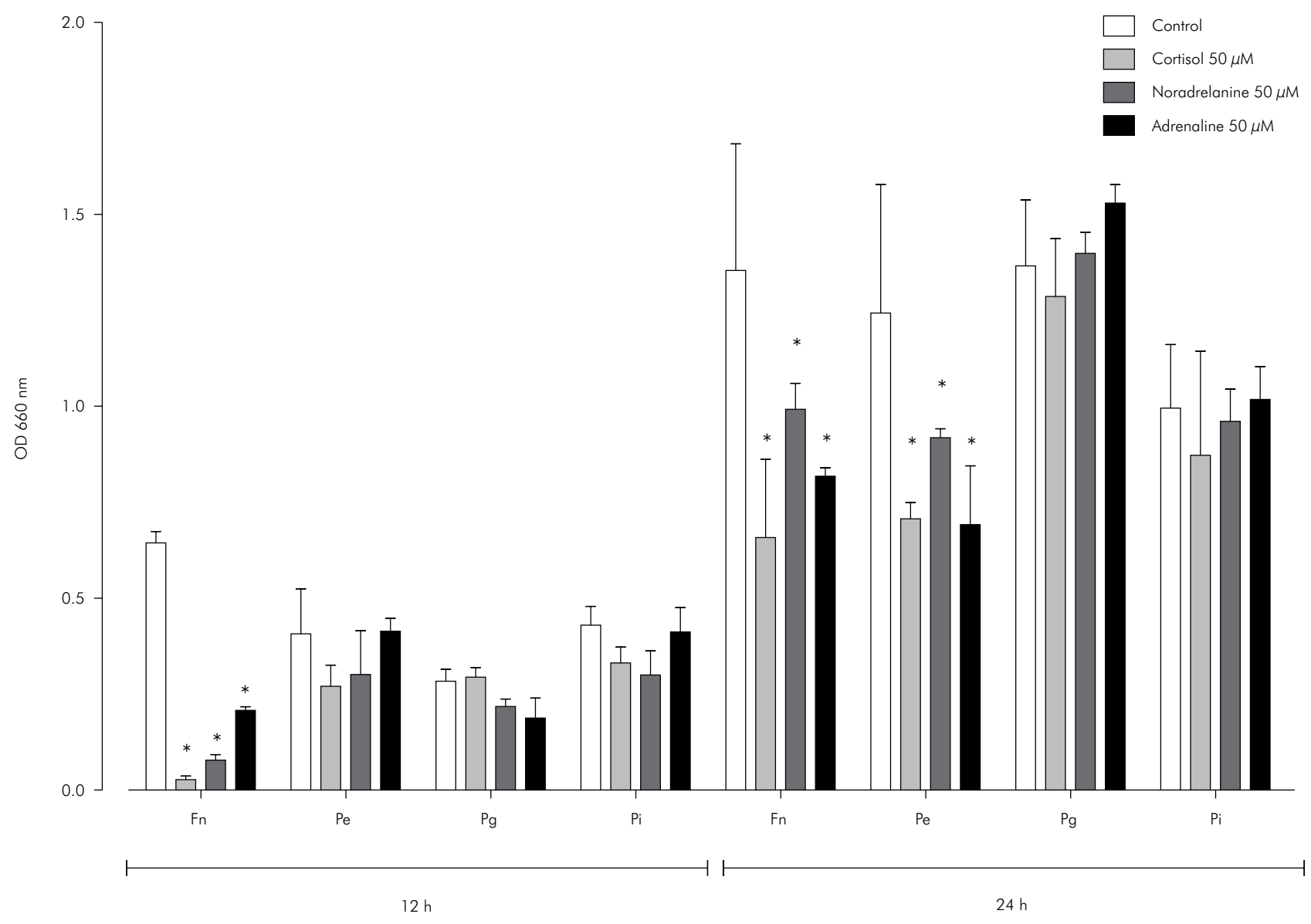

Figure 2. Mean and standard deviation of optical density $(660 \mathrm{~nm})$ representing the bacterial growth. Statistically significant $p$ values are shown $(*)$ on the upper side of the columns $(p<0.05$, Kruskal Wallis, Dunn).

(Kruskal-Wallis, $p>0.05$ ). However, ADR and NA did increase the $\mathrm{H}_{2} \mathrm{~S}$ concentration in Fn cultures after 24 $\mathrm{h}$ of exposure $(p<0.05)$. Only $F n$ showed a reduction in $\mathrm{CH}_{3} \mathrm{SH}$ production by CORT after $24 \mathrm{~h}(p<0.05)$. No other conditions changed the $\mathrm{CH}_{3} \mathrm{SH}$ levels.

$\mathrm{H}_{2} \mathrm{~S}$ concentrations were significantly increased only in Pe cultures exposed to NA for $12 \mathrm{~h}(p<0.05)$. No difference in $\mathrm{H}_{2} \mathrm{~S}$ production was observed for the groups exposed to ADR and CORT ( $p>0.05)$. In addition, $\mathrm{CH}_{3} \mathrm{SH}$ levels were not altered by exposure of $P e$ to catecholamines and CORT ( $p>0.05)$.

No statistically significant differences $(p>0.05)$ were found in $\mathrm{H}_{2} \mathrm{~S}$ and $\mathrm{CH}_{3} \mathrm{SH}$ levels among groups and their respective controls in $P g$ cultured for 12 or $24 \mathrm{~h}$.

$P i$ was more sensitive to the effects of catecholamines and CORT than the other bacterial cultures. In this case, $\mathrm{H}_{2} \mathrm{~S}$ production was up-regulated in the groups exposed to ADR, CORT (12 and $24 \mathrm{~h}$ ) and NA
$(24 \mathrm{~h})(p<0.05)$. None of the experimental groups showed differences in $\mathrm{CH}_{3} \mathrm{SH}$ production compared to their controls $(p>0.05)$.

\section{Discussion}

Clinical evidence has shown that stress can increase VSC concentrations, thus contributing to halitosis. ${ }^{6}$ The present study provides additional support for the role of stress substances on halitosis, as it was shown that ADR, NOR and CORT can up-regulate the production of VSC by microorganisms commonly found in sub-gingival biofilms.

This study reveals a variation in the growth rates of four periodontopathogenic microorganisms in response to the addition of stress hormones to their culture media. The growth of $F n$ and $P e$ was reduced by stress hormones, primarily after $24 \mathrm{~h}$ of exposure. In contrast, no significant effects on growth 


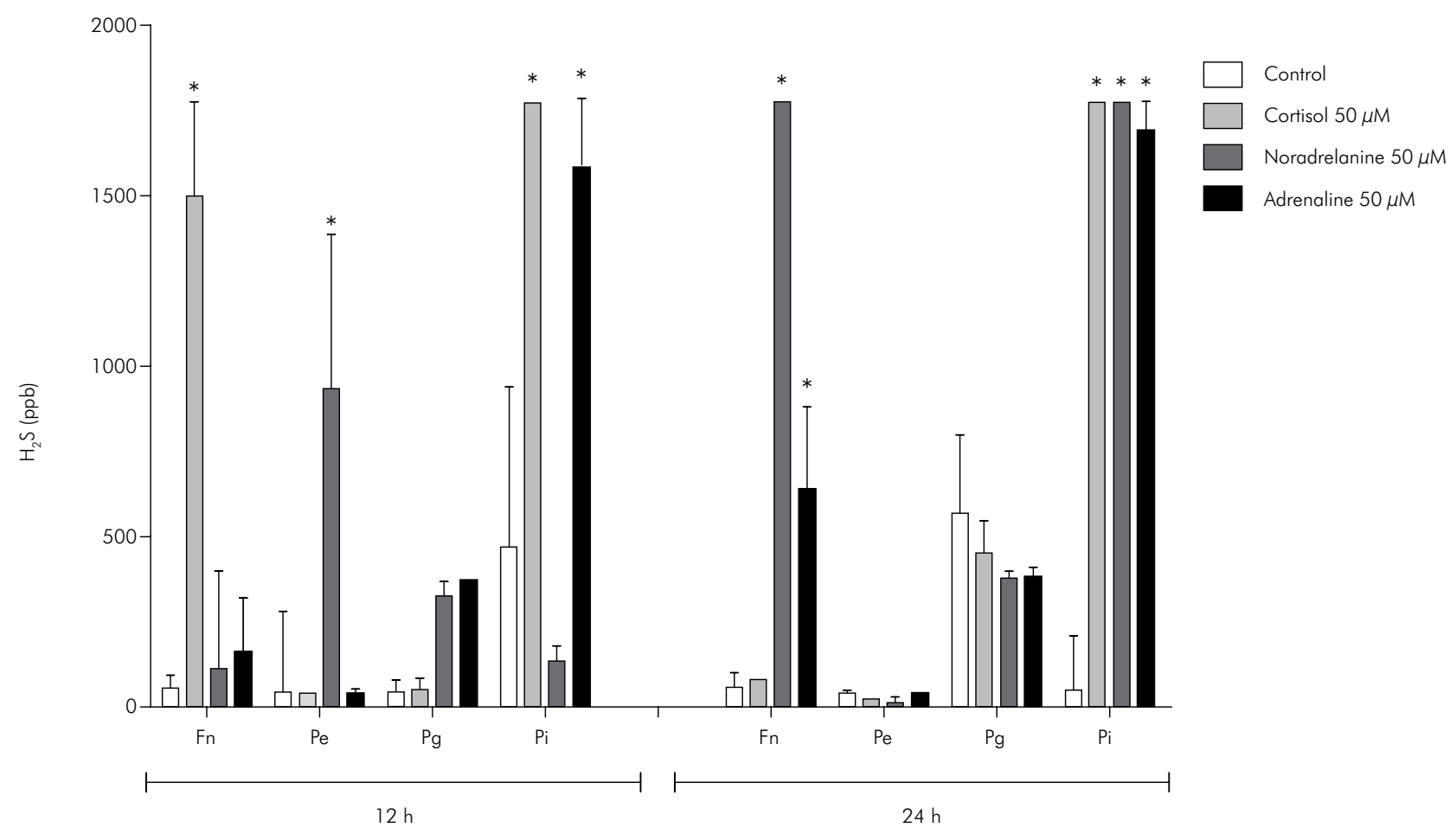

Figure 3. Median and interquartile deviation of $\mathrm{H}_{2} \mathrm{~S}$ concentrations (ppb) representing the VSCs production. Statistically significant $p$ values are shown $\left({ }^{*}\right)$ on the upper side of the columns ( $p<0.05$, Kruskal Wallis, Dunn).

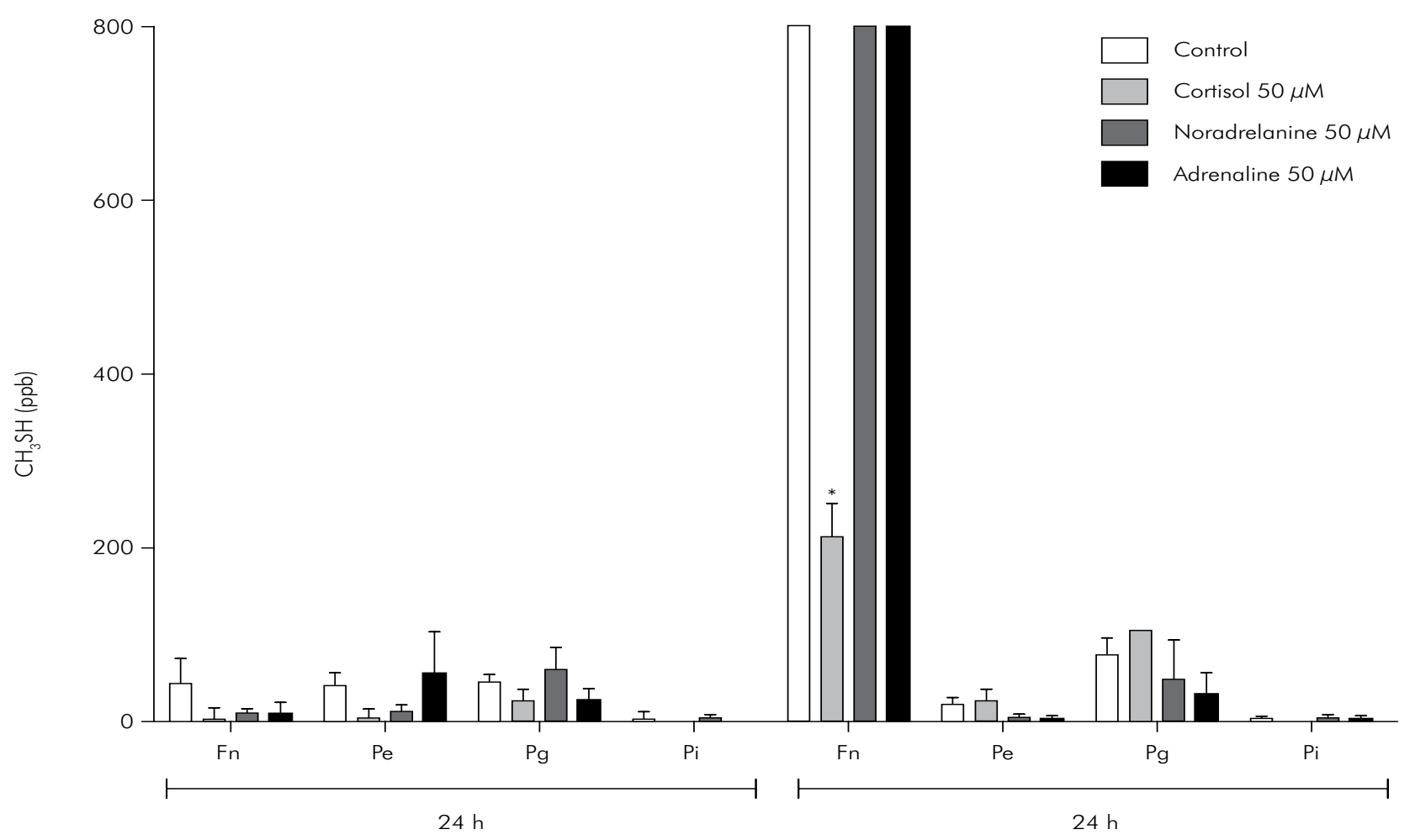

Figure 4. Median and interquartile deviation of $\mathrm{CH}_{3} \mathrm{SH}$ concentrations (ppb) representing the VSCs production. Statistically significant $p$ values are shown $\left({ }^{*}\right)$ on the upper side of the columns $(p<0.05$, Kruskal Wallis, Dunn). 
were observed in $P g$ and $P i$ for any of the substances tested. Most of these results are in agreement with the literature regarding the effects of catecholamines on bacterial growth. Roberts et al. ${ }^{13}$ demonstrated an inhibitory effect of catecholamines on $F n$ growth and no effect on the growth of $P i$ cultures, while Belay et al. ${ }^{12}$ and Jentsch et al. ${ }^{17}$ showed no change in $P g$ growth patterns. However, some of the present findings are contrary to previous reports. It was reported that the growth rate of $P g$ was reduced when exposed to catecholamines. ${ }^{13,15}$ Additionally, cortisol was demonstrated to stimulate the growth of $P g$ cultures. ${ }^{24}$ Our results showed no effects of NA, ADR or CORT on the growth rate of this pathogen. There were several differences in the experimental factors used in these studies, including the period of hormone exposure, bacterial strains and culture media used, catecholamine concentration and the method of growth assessment, which may have contributed to the divergent findings.

There are some reports in the literature demonstrating VSC production by periodontopathogenic bacteria. Previous studies revealed that saliva and dental plaque from patients with periodontal disease produces large quantities of VSC, thus contributing to malodor. ${ }^{25,26,27}$ Our study shows that periodontal bacteria produce significant VSC levels in vitro and that this production is altered by stress hormones. We observed that the major effects of catecholamines and CORT were on $\mathrm{H}_{2} \mathrm{~S}$ levels, mainly in the case of $\mathrm{Fn}, \mathrm{Pe}$ and $\mathrm{Pi}$. For these bacteria, exposure to these substances caused an increase in $\mathrm{H}_{2} \mathrm{~S}$ concentration. Only CORT changed the production of $\mathrm{CH}_{3} \mathrm{SH}$, and this effect was inhibitory in $F n$ cultures treated with this glucocorticoid. Given these results, it is possible to assume that the main roles of ADR, NA and CORT are in $\mathrm{H}_{2} \mathrm{~S}$ production. To better understand the effects of stress hormones, it will be necessary to utilize enzymatic, genomic and proteomic approaches.

Interestingly, the growth and VSC production of $P g$ was not affected by any of the stress hormones tested. It is possible that $P g$ is less sensitive to hormonal influence in the favorable environment of our experiment, which offered a rich-nutrient culture media along with controlled atmosphere and temperature. Previous studies have observed that adrenaline and noradrenaline have strong effects on bacterial growth mainly when the bacteria are cultivated in poor nutrient media. ${ }^{18,28}$ For this reason, those authors designed a special medium, serumSAPI minimal medium, to mimic the challenging in vivo environment. However, this medium was not used in our study. This could be the reason for our observations of slight effects of hormones on growth and VSC production, especially in the case of $P g$. It is possible, for example, that these organisms (and others showing negative growth responses) utilize catecholamines for up-regulation of virulence expression rather than for growth ${ }^{13}$ and VSC production.

When taking into consideration the times of exposure (12 and $24 \mathrm{~h}$ ) in our study, differing effects were found. In some experiments, significant effects of the hormones were noted at both times, while the hormone effects were observed at only one time period (12 or $24 \mathrm{~h}$ ) in other experiments. We expected to observe that a substance that showed an effect at $12 \mathrm{~h}$ of exposure would have the same effect at $24 \mathrm{~h}$. As demonstrated, however, this was not always the case. These stress-related substances have short halflives and could be degraded during the time-period of our experiments. Kennedy et al. ${ }^{29}$ demonstrated that catecholamines are stable in saliva for up to $2 \mathrm{~h}$ at $4{ }^{\circ} \mathrm{C}$. In our study, however, catecholamine concentrations in the culture medium after 12 and $24 \mathrm{~h}$ were not determined, and one can imagine that degradation was faster due to the higher temperature. We hypothesized that the bacteria might be able to use this degradation by-product to stimulate VSC production; however, further studies are necessary to elucidate this hypothesis. With regard to the degradation of CORT, it is known that this hormone remains stable in saliva at ambient temperature for up to one week or more ${ }^{30}$ and, therefore, would not be degraded during our experimental period.

By comparing the VSC production and growth patterns of bacteria exposed to NA, ADR and CORT, it was possible to observe differing results. These findings suggest a species-specific interaction of ADR, NA and CORT, which leads to differing effects in terms of growth and gas production. It is worth highlighting that, even in some situations where growth was reduced, VSC levels were stimulated. Because of this, 
it is possible that these stress-related substances have different cellular mechanisms whereby they affect growth and VSC production. Additionally, considering that fewer bacteria could produce higher levels of VSC in the presence of these hormones, it is important to evaluate the clinical importance of this observation. It is possible that these results could be the beginning of an explanation for why patients without advanced periodontal disease or other clinical signs of inflammation have increased complaints of halitosis in stressful situations and have higher VSC levels than non-stressed patients. ${ }^{6}$ Investigations of the exposure of catecholamines and cortisol in multi-species biofilm models, animal models for halitosis and clinical studies should be carried

\section{References}

1. Aylikci BU, Colak H. Halitosis: From diagnosis to management. J Nat Sci Biol Med. 2013 Jan;4(1):14-23.

2. Persson S, Claesson R, Carlsson J. The capacity of subgingival microbiotas to produce volatile sulfur compounds in human serum. Oral Microbiol Immunol. 1989 Sep;4(3):169-72.

3. Krespi YP, Shrime MG, Kacker A. The relationship between oral malodor and volatile sulfur compound-producing bacteria. Otolaryngol Head Neck Surg. 2006 Nov;135(5):671-6.

4. Peruzzo DC, Benatti BB, Ambrosano GM, Nogueira-Filho GR, Sallum EA, Casati MZ, et al. A systematic review of stress and psychological factors as possible risk factors for periodontal disease. J Periodontol. 2007 Aug;78(8):1491-504.

5. Rosania AE, Low KG, McCormick CM, Rosania DA. Stress, depression, cortisol, and periodontal disease. J Periodontol. 2009 Feb;80(2):260-6.

6. Calil CM, Marcondes FK. Influence of anxiety on the production of oral volatile sulfur compounds. Life Sci. 2006 Jul 10;79(7):660-4.

7. Ng SK, Keung Leung W. A community study on the relationship between stress, coping, affective dispositions and periodontal attachment loss. Community Dent Oral Epidemiol. 2006 Aug;34(4):252-66.

8. Ishisaka A, Ansai T, Soh I, Inenaga K, Yoshida A, Shigeyama $\mathrm{C}$, et al. Association of salivary levels of cortisol and dehydroepiandrosterone with periodontitis in older Japanese adults. J Periodontol. 2007 Sep;78(9):1767-73.

9. Huang S, Lu F, Zhang Z, Yang X, Chen Y. The role of psychologic stress-induced hypoxia-inducible factor-1alpha in rat experimental periodontitis. J Periodontol. 2011 Jun;82(6):934-41.

10. Semenoff TA, Rosa Junior A, Borges AH, Porto AN, Caporossi C, Semenoff Segundo A. Effect of chronic stress in newborn rats on the progression of ligature-induced-periodontitis in adulthood. Acta Cir Bras. 2013 Sep;28(9):652-6. out to better understand the relationship of stress and VSC production.

\section{Conclusions}

In conclusion, our results indicate that the hormones adrenaline, noradrenaline and cortisol can modulate the growth of periodontopathogenic microorganisms and the production of VSC, thus elucidating another possible mechanism of action for the relationship between stress and the development of halitosis.

\section{Acknowledgements}

We thank Fundação de Amparo à Pesquisa do Estado de São Paulo (Fapesp) for its support. GMO was the recipient of a Fapesp fellowship (no. 2008/00750-1).

11. Freestone PP, Sandrini SM, Haigh RD, Lyte M. Microbial endocrinology: how stress influences susceptibility to infection. Trends Microbiol. 2008 Feb;16(2):55-64.

12. Belay T, Aviles H, Vance M, Fountain K, Sonnenfeld G. Catecholamines and in vitro growth of pathogenic bacteria: enhancement of growth varies greatly among bacterial species. Life Sci. 2003 Aug 8;73(12):1527-35.

13. Roberts A, Matthews JB, Socransky SS, Freestone PP, Williams PH, Chapple IL. Stress and the periodontal diseases: effects of catecholamines on the growth of periodontal bacteria in vitro. Oral Microbiol Immunol. 2002 Oct;17(5):296-303.

14. Roberts A, Matthews JB, Socransky SS, Freestone PP, Williams PH, Chapple IL. Stress and the periodontal diseases: growth responses of periodontal bacteria to Escherichia coli stress-associated autoinducer and exogenous Fe. Oral Microbiol Immunol. 2005 Jun;20(3):147-53.

15. Saito T, InagakiS, Sakurai K, Okuda K, Ishihara K. Exposure of P. gingivalis to noradrenaline reduces bacterial growth and elevates ArgX protease activity. Arch Oral Biol. 2011 Mar;56(3):244-50.

16. Pullinger GD, Carnell SC, Sharaff FF, van Diemen PM, Dziva F, Morgan E, et al. Norepinephrine augments Salmonella enterica-induced enteritis in a manner associated with increased net replication but independent of the putative adrenergic sensor kinases QseC and QseE. Infect Immun. 2010 Jan;78(1):372-80.

17. Jentsch HF, März D, Krüger M. The effects of stress hormones on growth of selected periodontitis related bacteria. Anaerobe. 2013 Dec;24:49-54

18. Lyte M, Ernst S. Catecholamine induced growth of gram negative bacteria. Life Sci. 1992;50(3):203-12.

19. Plotkin BJ, Roose RJ, Erikson Q, Viselli SM. Effect of androgens and glucocorticoids on microbial growth and antimicrobial susceptibility. Curr Microbiol. 2003 Dec;47(6):514-20. 
20. Tanabe S, Desjardins J, Bergeron C, Gafner S, Villinski JR, Grenier D. Reduction of bacterial volatile sulfur compound production by licoricidin and licorisoflavan A from licorice. J Breath Res. 2012 Mar;6(1):016006.

21. Winn Jr WC, Janda WM, Koneman EW, Schreckenberger PC, Procop GW, Woods GL. Koneman's color atlas and textbook of diagnostic microbiology. 6th ed. Philadelphia: Lippincott Willians \& Wilkins Company; 2006. 1531 p.

22. Winkel EG, Tangerman A. Appropriate sample bags and syringes for preserving breath samples in breath odor research: a technical note. J Breath Res. 2008 Mar;2(1):017011.

23. Tangerman A, Winkel EG. Extra-oral halitosis: an overview. J Breath Res. 2010 Mar;4(1):017003.

24. Akcali A, Huck O, Buduneli N, Davideau JL, Kose T, Tenenbaum $\mathrm{H}$. Exposure of Porphyromonas gingivalis to cortisol increases bacterial growth. Arch Oral Biol. 2014 Jan;59(1):30-4.

25. Coli JM, Tonzetich J. Characterization of volatile sulphur compounds production at individual gingival crevicular sites in humans. J Clin Dent. 1992;3(4):97-103.
26. Yaegaki K, Sanada K. Biochemical and clinical factors influencing oral malodor in periodontal patients. J Periodontol. 1992 Sep;63(9):783-9.

27. Kishi M, Ohara-Nemoto Y, Takahashi M, Kishi K, Kimura $\mathrm{S}$, Aizawa F, et al. Prediction of periodontopathic bacteria in dental plaque of periodontal healthy subjects by measurement of volatile sulfur compounds in mouth air. Arch Oral Biol. 2013 Mar;58(3):324-30.

28. O'Donnell PM, Aviles H, Lyte M, Sonnenfeld G. Enhancement of in vitro growth of pathogenic bacteria by norepinephrine: importance of inoculum density and role of transferrin. Appl Environ Microbiol. 2006 Jul;72(7):5097-9.

29. Kennedy B, Dillon E, Mills PJ, Ziegler MG. Catecholamines in human saliva. Life Sci. 2001 May 25;69(1):87-99.

30. Liening SH, Stanton SJ, Saini EK, Schultheiss OC. Salivary testosterone, cortisol, and progesterone: two-week stability, interhormone correlations, and effects of time of day, menstrual cycle, and oral contraceptive use on steroid hormone levels. Physiol Behav. 2010 Jan 12;99(1):8-16. 